\title{
Ideal Kidney Oxygenation during Normothermic Machine Perfusion
}

\author{
Thomas D Adams ${ }^{1,2}$, Tom Moore ${ }^{1}$, Keziah Crick², Corrina Fear², Diogo Fouto², \\ Sarah A Hosgood ${ }^{1,2}$, Michael L Nicholson ${ }^{1.2}$ \\ ${ }^{1}$ University of Cambridge, ${ }^{2}$ Cambridge University Hospitals
}

Normothermic Machine Perfusion (NMP) is a new technique for assessing, conditioning, and treating marginal donor kidneys. It aims to increase kidney transplantation following donation after cardiac death (DCD) $1^{1,2}$

Perfusion systems have historically supplied a gas mixture of $95 \% \mathrm{O}_{2}$ and $5 \% \mathrm{CO}_{2}$, but evidence suggests that supraphysiological oxygen delivery can be deleterious. ${ }^{3,4}$

We hypothesised that excess oxygenation of donor kidneys during perfusion may exacerbate ischaemic injury or abate the conditioning effect of NMP.

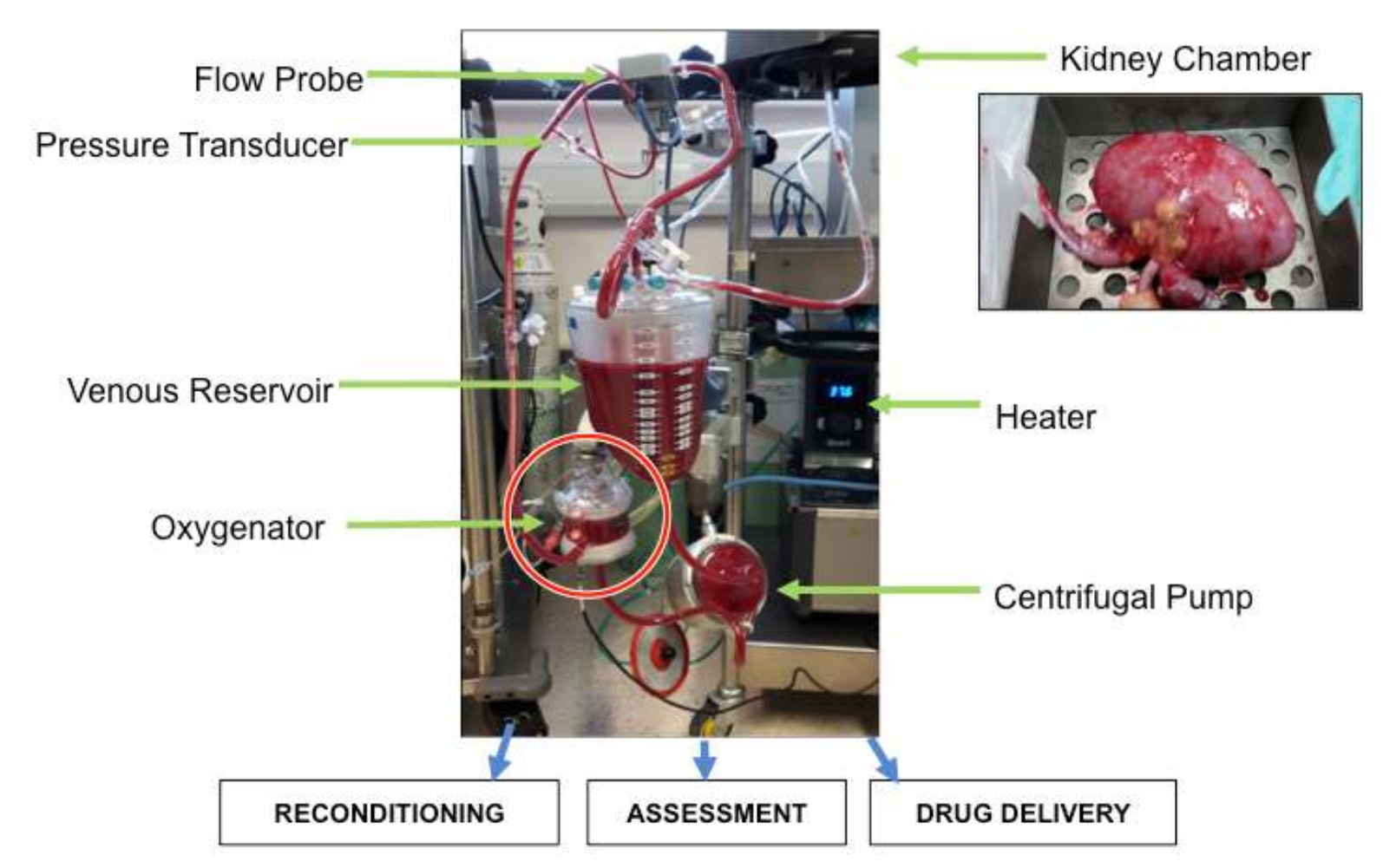

Study 2: Oxygenation and Reperfusion Injury / NMP conditioning
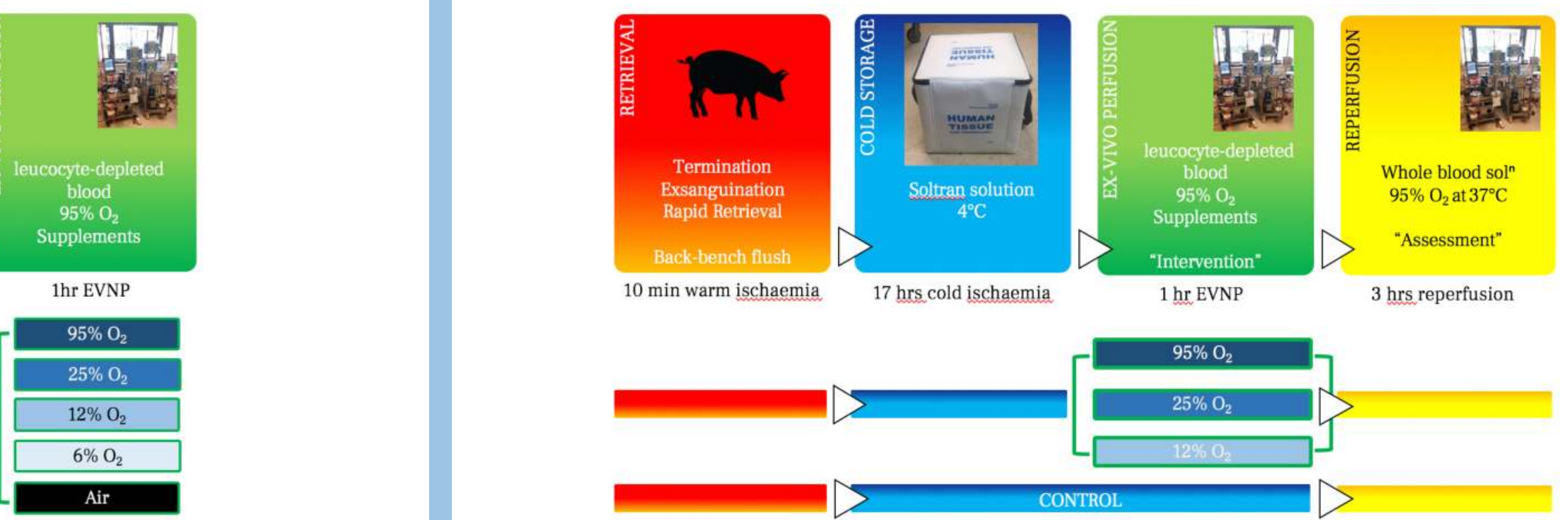

Renal Blood Flow

Oxygen Consumption $\left(\mathrm{VO}_{2}\right)$
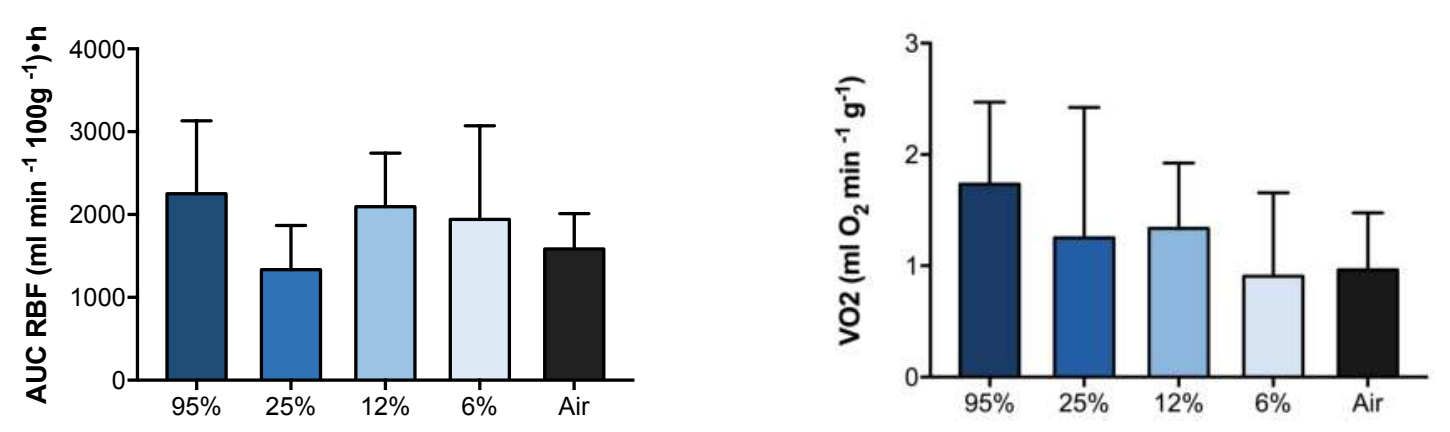

Fractional Excretion of Sodium $\left(\mathrm{FE}_{\mathrm{Na}}\right)$
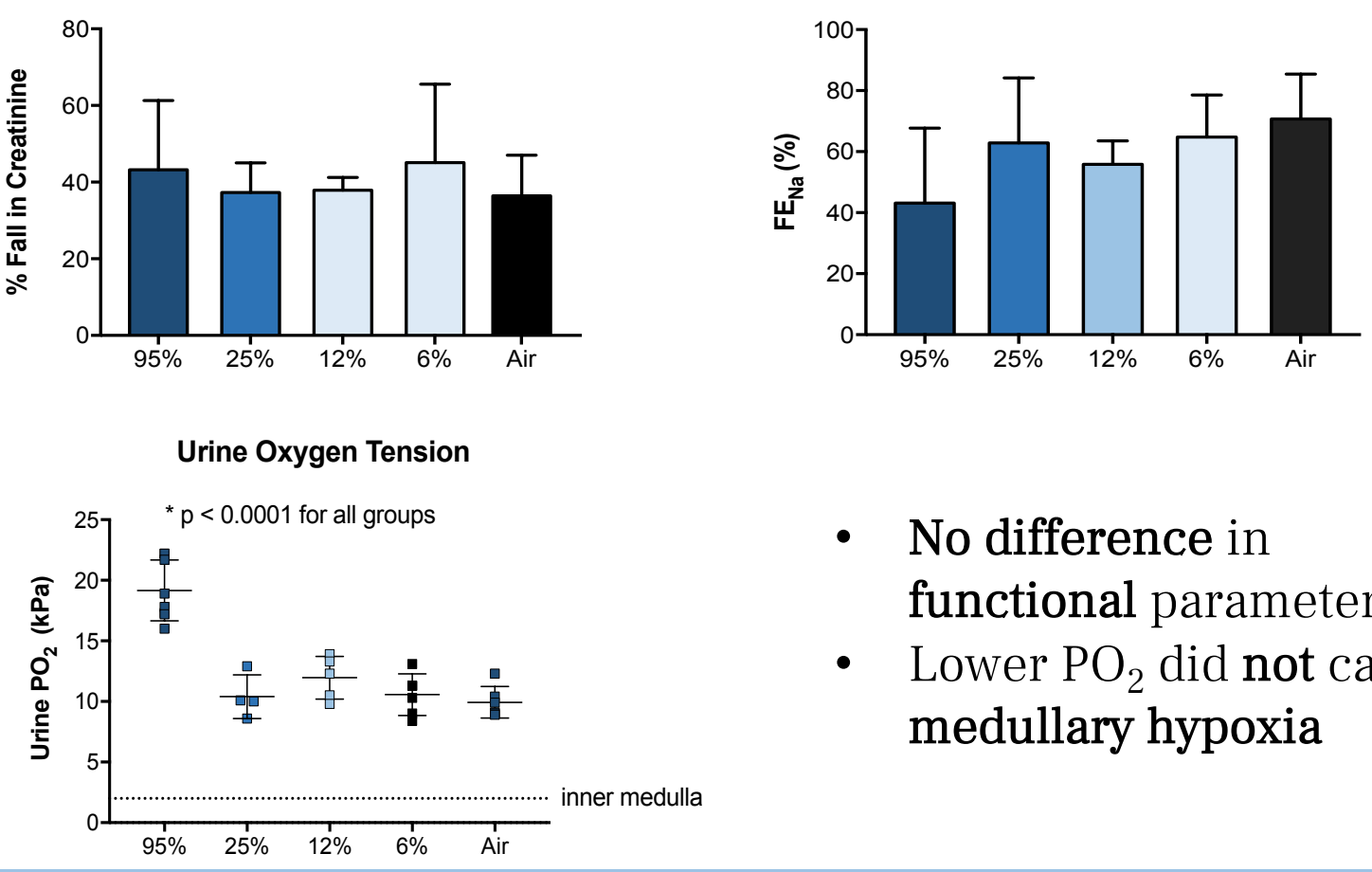

- No difference in functional parameters

- Lower $\mathrm{PO}_{2}$ did not cause medullary hypoxia


Tissue HMGB-1

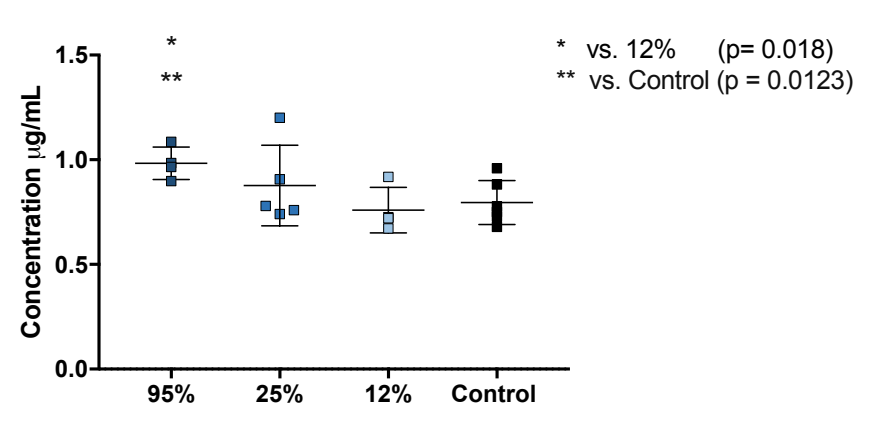

\section{$\underline{\text { Conclusions }}$}

\section{During NMP:}

- Kidneys effectively autoregulate $\mathrm{VO}_{2}$ to $\mathrm{RBF}$

- Lower $\mathrm{PO}_{2}$ did not adversely affect renal function

- Lower $\mathrm{PO}_{2}$ did not lead to medullary hypoxia

\section{During Reperfusion:}

- Overall, lower $\mathrm{PO}_{2}$ did not worsen reperfusion injury

- Lower $\mathrm{PO}_{2}$ may be more protective than $95 \% \mathrm{O}_{2}$

\section{References}

1. Hosgood SA, Patel M, Nicholson ML. J Surg Res. 2013;182(1):153-160

2. Hosgood SA, Barlow AD, Hunter JP, Nicholson ML. Br J Surg. 2015;102(11):1433-1440,

3. Evans RG, Gardiner BS, Smith DW, O'Connor PM. Am J Physiol - Ren Physiol. 2008;295(5):F1259-F1270.

4. Martin DS, Grocott MPW. Crit Care Med. 2013;41(2):423-432.

. Ricksten S-E, Bragadottir G, Redfors B. Crit Care. 2013;17(2):221.

7. Granger DN, Kvietys PR. Redox Biol. 2015;6:524-551.

圈 UNIVERSITY OF CAMBRIDGE Department of Surgery 